\title{
CELLULAR HYPOXIA: A KEY MODULATOR OF ADIPOCYTE FUNCTION IN OBESITY?
}

\section{Paul Trayhurn, Fátima Pérez de Heredia, Bohan Wang, Cristiane de Oliveira, Pedro González-Muniesa, and I. Stuart Wood}

Obesity Biology Research Unit, School of Clinical Sciences, University of Liverpool, University Clinical Departments, Liverpool, United Kingdom

\section{Abstract}

We have proposed that hypoxia develops in adipose tissue (white) as tissue mass expands in obesity, this leading to the inflammatory response which is considered to underpin the development of obesity-associated diseases. Direct evidence for hypoxia in adipose tissue in obesity has now been obtained in mice and in humans. Studies on adipocytes, both human and murine, in cell culture have shown that the expression and release of several inflammation-related adipokines, such as IL-6, leptin and VEGF are stimulated by low $\mathrm{pO}_{2}$. The production of adiponectin, which has anti-inflammatory and insulin-sensitising actions, is, however, inhibited. Glucose uptake and the release of lactate are increased in adipocytes by hypoxia, with a corresponding increase in the level of the GLUT1 and MCT1 transporters, consistent with a switch to glycolytic metabolism. In preadipocytes, which do not normally synthesise leptin, low $\mathrm{pO}_{2}$ leads to induction of the expression and secretion of this key hormone. Recent studies suggest that there are important interactions between hypoxia and specific long-chain fatty acids in the production of inflammation-related adipokines. It is suggested that hypoxia has a pervasive effect on adipocyte physiology and is central to the dysregulation of adipose tissue function that occurs in obesity.

Adipobiology 2009; 1: 19-26

Key words: adipokines, adipose tissue, HIF-1, inflammation, $\mathrm{pO}_{2}$

Received 30 July 2009, accepted 25 August 2009.

Correspondence and reprint request: Professor Paul Trayhurn FRSE, Obesity Biology Research Unit, School of Clinical Sciences, University of Liverpool, Duncan Building, Liverpool L69 3GA, UK. Tel.: 44151706 4033, Fax: 44151706 5802,

Email: p.trayhurn@liverpool.ac.uk

\section{Introduction}

Hypoxia has traditionally been viewed as a phenomenon associated with high altitude and deep sea diving. Animals that live at altitude, or undergo deep dives, have evolved a series of physiological adaptations in order to adjust to the challenge of a lack of oxygen. In the case of altitude, these adaptations may be chronic for those species that live at high elevations. Hypoxia has also been associated with certain pathological conditions, such as wound healing, ischaemic damage and the interior of tumours $(1,2)$. Solid tumours may be extremely hypoxic, and so much so that in their centre there may be minimal $\mathrm{O}_{2}$ and the local environment can be essentially anoxic $(1,2)$.

Hypoxia is now increasingly understood to be a challenge to which specific cells are exposed in animals that live under conditions of normal environmental $\mathrm{O}_{2}$ pressure. In a number of tissues, the $\mathrm{O}_{2}$ tension has been shown to be well below that of arterial blood or of the general level of tissue oxygenation (2). Thus, while the $\mathrm{pO}_{2}$ of arterial blood is around 104 $\mathrm{mmHg}$ and general tissue oxygenation 
is 40-50 $\mathrm{mmHg}, \mathrm{pO}_{2}$ values well below this have been reported for tissues such as the brain, spleen and retina (2). In the case of solid tumours, the $\mathrm{pO}_{2}$ can be as little as $1 \mathrm{mmHg}$, or even lower.

The possibility that hypoxia occurs in adipose tissue in obesity was first raised by our group in 2004 (3). It was suggested that as adipose tissue mass expands clusters of large adipocytes become distant from the vasculature, resulting in relative hypoxia because of the reduced availability of $\mathrm{O}_{2}$. The normal diffusion distance of $\mathrm{O}_{2}$ across tissues is of the order of 100-200 $\mu \mathrm{m}$, and in some instances the $\mathrm{O}_{2}$ tension has been reported to be close to zero at $100 \mu \mathrm{M}$ from the vasculature (2). Since adipocytes are large cells, reaching up to $150 \mu \mathrm{m}$, or even $200 \mu \mathrm{m}$, in diameter in obesity (4), it is clearly probable that they can become hypoxic. The 'hypoxia hypothesis' proposes that localised $\mathrm{O}_{2}$-deprivation in large fat cells leads to an inflammatory response in order to increase blood flow and to stimulate angiogenesis $(3,5)$.

In this article, we consider the multiple effects of hypoxia on the function of adipocytes as the dominant and characteristic cell type within adipose tissue. We focus on our studies of human adipocytes since the most extensive investigations so far have been done on the fat cells of man.

\section{White adipose tissue and inflammation}

Mature adipocytes amount to about $50 \%$ of the total cell content of the major white adipose tissue depots, but this can vary according to site, age, and other factors. The adipocyte is a major secretory cell, releasing not only fatty acids as a fuel for other organs during periods of negative energy balance, but also a multiplicity of other substances. These include lipid moieties such as prostaglandins and endocannabinoids, and a rapidly growing number (up to 100 to date) of protein factors and signals - the adipokines $(3,6,7)$. The various protein factors and signals constitute the 'adipokinome'. Since several adipokines, notably leptin and adiponectin, are hormones, adipocytes have become recognised as major endocrine cells. The adipokines are highly diverse in terms of function, being involved in appetite and energy balance, vascular haemostasis, blood pressure regulation, angiogenesis, lipid metabolism and insulin sensitivity $(3,6-9)$.

Adipocytes secrete a number of cytokines, chemokines and acute phase proteins and other proteins related to inflammation and the inflammatory response $(3,6-9)$. Indeed, in obesity there is a state of inflammation in the tissue which is reflected in an increased circulating level of several inflammatory markers, including C-reactive protein, interleukin-6 (IL-6), plasminogen activator inhibitor-1 (PAI-1) and haptoglobin $(10,11)$. The expression and secretion of a number of inflammation-related adipokines is markedly elevated in adipose tissue in obesity; these include IL-6, tumor necrosis factor-alpha (TNF- $\alpha$ ), monocyte chemoattractant protein-1 (MCP1), PAI-1, visfatin and apelin $(3,10,11)$. However, in contrast to these factors the production and circulating level of the adipocyte-derived hormone adiponectin declines with increased adipose tissue mass (12).

The inflammatory response in adipose tissue in obesity and the major changes in the production of inflammation-related adipokines have been widely linked to the development of several obesity-associated diseases, particularly insulin resistance and the metabolic syndrome $(8,9,11,13)$. Indeed, the link between inflammatory adipokines, insulin resistance and the metabolic syndrome is a crucial concept in obesity. However, the basis for the inflammatory response in adipose tissue as obesity develops has not been clear and the hypoxia hypothesis (3) is a direct attempt to address the issue.

The main pathway by which a low $\mathrm{pO}_{2}$ is signalled within cells involves the recruitment of hypoxia-sensitive transcription factors. Several such factors have been described, including CREB and NFkB (14). However, the most important pathway is through the HIF-1 (hypoxia-inducible factor 1) transcription factor. HIF- 1 consists of $1 \alpha$ and $1 \beta$ subunits, HIF- $1 \beta$ being constitutively expressed $(1,2,15)$. There are three different forms of the HIF- $\alpha$ subunit, namely $-1 \alpha,-2 \alpha$ and $-3 \alpha$ (forming the corresponding transcription factors, HIF-1, HIF-2 and HIF-3), the breakdown of which occurs in the presence of $\mathrm{O}_{2}(15)$. The most important appears to be HIF- $1 \alpha$, which is stabilised when $\mathrm{O}_{2}$ tension is low, enabling the functional transcription factor to be recruited (see Fig. 1), which binds to hypoxia response elements on a number $(>70)$ of genes.

\section{Hypoxia in adipose tissue}

The occurrence of hypoxia in white fat depots in obesity has now been directly observed in obese mice. Hypoxia has been shown in mice made obese through the consumption of a high fat diet, and in obese ob/ob and KKAy mice (16-18). Two different approaches have been used to examine adipose tissue for hypoxia in obese mice - staining with pimonidazole ('Hypoxyprobe'), a chemical marker of hypoxia, and measurements with an $\mathrm{O}_{2}$ electrode. While the pimonidazole method is essentially a qualitative procedure (although relative quantitation is possible by western blotting), the studies with an $\mathrm{O}_{2}$ electrode have indicated that the $\mathrm{pO}_{2}$ in the adipose tissue of obese mice is around $15 \mathrm{mmHg}$, as compared with $45-50 \mathrm{mmHg}$ in the lean (17).

The studies showing hypoxia in adipose tissue in obese mice have recently been followed by similar results in humans for the abdominal subcutaneous fat depot (19). An inverse correlation between percent body fat and $\mathrm{pO}_{2}$ in adipose tissue was demonstrated. However, the degree of hypoxia with increasing fatness was relatively small in the human study and did not lead 
Normoxia Hypoxia

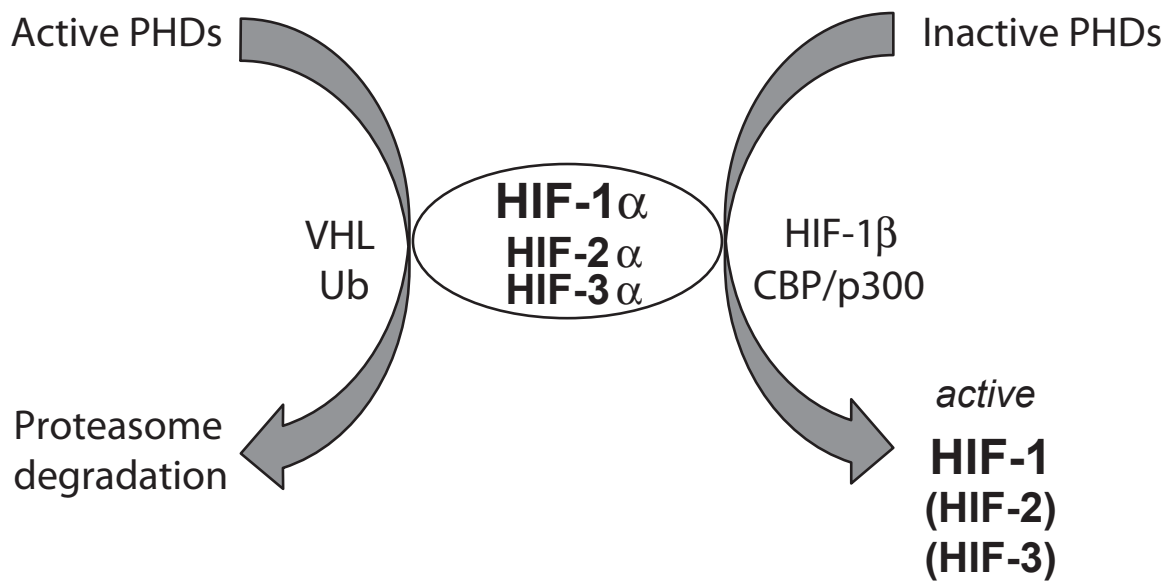

Figure 1. Overview of the recruitment of the HIF-1 transcription factor (and HIF-2 and -3) in response to hypoxia. HIF-1 binds to hypoxia response elements in a number of genes. HIF-1a, hypoxic inducible factor-1a; HIF-2a, hypoxic inducible factor-2a; HIF-3a, hypoxic inducible factor-3a; PHD, propyl hydrogenase domain proteins; VHL, von Hippel Lindau protein; Ub, ubiquitin; HIF-1b, hypoxic inducible factor-1b subunit; CBP/p300, cAMP binding protein binding protein/p300 subunit.

to the activation of the classical target genes of low $\mathrm{O}_{2}$ tension (19). Further work is clearly needed on humans, and in exploring both in man and in animals whether there is a link between the degree of obesity and the extent of hypoxia.

Analysis of adipose tissue of obese animals has demonstrated that the level of HIF-1a protein is increased (17), indicative of hypoxia. It is important to note, as we have done previously, that HIF-1a mRNA level is not a suitable marker of hypoxia; it is essential to measure HIF-1a protein since the mRNA level is reduced, rather than raised, under low $\mathrm{O}_{2}$ tension (20). GLUT1 mRNA levels are increased in adipose tissue in obese mice (17), consistent with a state of hypoxia since GLUT1 is well-recognised as a hypoxia-sensitive gene. Lactate levels are also raised, which is suggestive of a switch to glycolytic metabolism, and this is selective to adipose tissue with no increase in muscle lactate (16). Blood flow measurements with radioactively-labelled microspheres show reduced perfusion of adipose tissue in obese mice, and again this is specific to the tissue since the number of microspheres in muscle, kidney, lung and heart were unchanged (16).

The expression of several genes encoding inflammation-related adipokines is increased in adipose tissue in obesity, including IL-6, leptin, PAI-1 and macrophage migration inhibitory factor (MIF) $(16,17)$. On the other hand, the expression of adiponectin, with its anti-inflammatory and insulin-sensitising actions, is reduced. Although these changes in inflammatory adipokine expression are consistent with hypoxia, they are not necessarily a direct response to low $\mathrm{O}_{2}$ tension and other factors may be involved.

\section{Hypoxia in human adipocytes}

In vitro studies using cell culture have been employed to explore the extent to which various adipokine genes are modulated by low $\mathrm{O}_{2}$ tension. This has been investigated in several studies, including in relation to angiogenesis (21) prior to the development of the hypoxia hypothesis. Although the effects of hypoxia on fat cells have been examined in rodent adipocyte systems $(16,17,21,22)$, such as the 3T3-L1 clonal cell line, studies have also been conducted on human adipocytes (23-25). In our own work on human adipocytes, we have used both adipocytes differentiated from fibroblastic preadipocytes in primary culture (from Zen-Bio) and SGBS (Simpson-Golabi-Behmel Syndrome) cells (26). The latter are a cell strain in which preadipocytes have a high capacity for differentiation into mature adipocytes.

The basic protocol that we have employed in our studies, which is broadly similar to that of other groups, is to take adipocytes at 10-15 days after the induction of differentiation, and to incubate them under either normoxic $\left(21 \% \mathrm{O}_{2}\right)$ or hypoxic $\left(1 \% \mathrm{O}_{2}\right)$ conditions for up to $24 / 48 \mathrm{~h}$. The level of hypoxia chosen is relatively standard in in vitro studies investigating the effects of low $\mathrm{O}_{2}$ tension, and the measurements in adipose tissue of obese animals suggest that it is equivalent to $2 \% \mathrm{O}_{2}\left(1 \% \mathrm{O}_{2}\right.$ equates to a $\mathrm{pO}_{2}$ of $7.6 \mathrm{mmHg}$ ). Furthermore, it appears that the cellular responses to hypoxia, at least in terms of the recruitment 
of HIF-1, occurs at and below $5 \% \mathrm{O}_{2}(2)$. Although most studies of adipocytes in culture have used $1 \% \mathrm{O}_{2}$, there is a need to examine the response to differing levels of $\mathrm{O}_{2}$ ( $5 \%$ and below) to determine the extent to which the expression of various hypoxia-sensitive genes is modulated by different degrees of hypoxia.

\section{Adipokines}

Incubation of human adipocytes under hypoxic conditions upregulates the expression of several inflammation-related adipokines. Thus the mRNA level of leptin, angiopoietin-like protein 4 (Angplt4 - also known as fasting-induced adipose factor) IL6, MIF, PAI-1 and vascular endothelial growth factor (VEGF) were increased over $24 \mathrm{~h}$ (23). In the case of leptin, Angptl4 and VEGF the increases were substantial ( $>10$-fold rise in mRNA). In contrast, adiponectin mRNA was decreased (23). Similar results have been reported for murine fat cells in most cases, including particularly leptin, PAI-1 and adiponectin $(16,17,21,22)$. Importantly, the alterations in gene expression in response to hypoxia are mirrored by parallel changes in the release of the adipokines themselves into the medium of the cultured adipocytes $(22,23)$. Studies with the hypoxia mimetic $\mathrm{CoCl}_{2}$, which leads to the stabilisation of HIF-1 1 with the recruitment of functional HIF-1, indicate that in most cases the transcription of inflammatory adipokine genes is HIF-1 dependent (23).

The hypoxia-induced changes in adipokine production and release are consistent with the concept that $\mathrm{O}_{2}$-deprivation underpins the development of inflammation in white adipose tissue in obesity. However, there are no changes in the expression of some key inflammatory adipokines such as TNF- $\alpha$ and MCP1 , at least in human adipocytes (23). Furthermore, subsequent studies have shown that IL- $1 \beta$ expression is reduced rather than increased in these adipocytes by hypoxia (27). Overall, it is evident that some, but by no means all, major inflammation-related genes are modulated in adipocytes by hypoxia.

\section{PCR arrays and microarrays}

A 'candidate gene' approach has been the most widely used strategy for examining the effects of hypoxia on gene expression in adipocytes. However, we have also employed PCR arrays for the hypoxia signalling pathway in which the expression of a panel of 85 hypoxia-sensitive genes was probed simultaneously by realtime PCR (28). Application of these arrays to human adipocytes in culture has confirmed the hypoxia-sensitivity of several key genes in fat cells, including GLUT1, leptin, Angpt14 and VEGF. Several other genes were also identified as being sensitive to low $\mathrm{O}_{2}$ tension in adipocytes, including UCP2 and catalase (28). The expression of one particular gene, MT3 - a member of the metallothionein family - was found to be dramatically induced by hy- poxia, a $>600$-fold increase in MT3 mRNA level being observed over $24 \mathrm{~h}(28)$.

The induction of MT3 gene expression in response to hypoxia was rapid ( 100-fold increase in mRNA level in $60 \mathrm{~min})$, selective to MT3 rather than other metallothioneins (MT2A mRNA level changed <2-fold) and HIF-1 dependent (28). However, MT3 itself was not detected in the adipocytes, but this may have been a reflection of the lack of sensitivity of the antibodies used to detect the protein. MT3 is suggested to be protective against toxic challenge, and a rapid and substantial induction of MT3 expression has been described in astrocytes in culture where it is suggested that the protein plays a role in the protection of the brain against hypoxic damage (29). A similar protective function against hypoxic stress, including oxidative damage, may also underlie MT3 induction in adipocytes.

In a recent collaborative study, Agilent microarrays were used to screen the effects of hypoxia on global gene expression in human adipocytes (Trayhurn et al, unpublished results). These arrays contain 44,000 probes and the expression of $>1200$ genes was found to be modulated by hypoxia using the stringent criteria of a $>2.0$-fold difference in mRNA level (at $P<0.01$ ). Of these, $>650$ were up-regulated and $>600$ down-regulated. The genes that were upregulated included two members of the aquaporin $(A Q P)$ family of water transporters, aquaporin-3 and -5 , while among those down-regulated were the peroxisome proliferative activated receptor $\gamma$ coactivator- $1 \alpha($ PPARGC1A) and fatty acid binding protein 5 (FABP5). Overall, the full array studies demonstrate that hypoxia has a profound effect on gene expression in human adipocytes. Full analysis of the microarray data is currently underway.

\section{Glucose metabolism}

The discussion so far has centred on adipokine production and this has been the main focus of studies on adipocytes in culture. The facilitative glucose transporter, GLUT1, is a hypoxia-sensitive marker gene and is up-regulated, as noted above, in adipose tissue in obesity and in adipocytes in response to low $\mathrm{O}_{2}$ tension. A study on the effects of hypoxia on the panel of facilitative glucose transporters expressed by human adipocytes found no effects over $24 \mathrm{~h}$ on GLUT4, GLUT10 and GLUT12 mRNA level, but GLUT1, GLUT3 and GLUT5 expression was increased (24). GLUT1 protein was also markedly increased (approximately 10fold), suggesting that the capacity for glucose transport is raised by exposure to low $\mathrm{O}_{2}$ tension. That this is indeed the case was demonstrated by studies with 2-deoxy-D-glucose, the uptake of which was 3-fold higher in human adipocytes in hypoxia than in normoxia (24). Such a response reflects the reduction in oxidative metabolism in conditions of low $\mathrm{pO}_{2}$ and the consequent 
increased need to generate ATP by glycolysis.

One of the implications of increased glucose utilisation in hypoxia is that the production of lactate would be expected to increase. In a recent study, we have found that lactate release by human adipocytes in cell culture is indeed raised (30). We also found that human adipocytes express three of the proton-linked monocarboxylate transporters (MCTs) responsible for the transport of lactate and similar metabolites across the plasma membrane (31), namely MCT1, MCT2 and MCT4. Both MCT1 and MCT4 are up-regulated by hypoxia in adipocytes, and MCT1, but not MCT4, protein is increased and this is HIF-1 dependent (30). In other cell types, MCT4 protein as well as gene expression has been shown to be augmented by hypoxia (32). Overall, hypoxia in adipocytes at the nutrient level leads to an increase in glucose uptake through the recruitment of additional GLUT1 transporters and this followed by increased lactate production which is removed from the cells by (in all probability) the recruitment of MCT1 transporters.

The fall in ATP production by oxidative metabolism that occurs in hypoxia involves adaptations at the mitochondrial level with improvements in the efficiency of oxidative phosphorylation (33). The main site of $\mathrm{O}_{2}$ consumption is at complex IV, which comprises cytochrome c oxidase subunit 4 (COX4). However, this is not a maximally efficient process and some leakage can occur at complex III, resulting in the generation of reactive oxygen species. Recent studies in several cell types have shown that under conditions of low $\mathrm{pO}_{2}$, the mitochondrial protease, LON, is up-regulated and that this leads to the degradation of the COX4-1 subunit $(33,34)$. This subunit is then replaced through the up-regulation of COX4-2, which increases the efficiency of respiration. We have now found that similar events occur in human adipocytes, there being an up-regulation of COX4-2 and LON expression in response to hypoxia, with an accompanying fall in the expression of COX4-1 (Wang et al, unpublished results).

\section{Insulin sensitivity}

Although incubation under low $\mathrm{O}_{2}$ tension for $24 \mathrm{~h}$ has no effect on the expression of the insulin sensitive transporter, GLUT4, more prolonged exposure ( $48 \mathrm{~h}$, or more) leads to a substantial fall in the mRNA level (35). This appears to be a specific effect, and not a result of cell damage, since GLUT1 mRNA level remains elevated and the alterations in GLUT1 and GLUT4 expression are reversed on return to normoxia (35). Such a change in GLUT4 expression clearly has implications for insulin sensitivity in adipose tissue. However, in two recent studies more acute exposure to hypoxia has been shown to lead to insulin resistance in adipocytes independent of any change in GLUT4.
Although the basal transport of glucose may be increased in hypoxia, 2-deoxy-D-glucose studies indicate that insulin-stimulated uptake is inhibited $(25,36)$. Furthermore, there are changes in the insulin signalling pathway, with for example a decrease in the phosphorylation of the insulin receptor and of components of the post-receptor signalling cascade $(25,36)$.

These are important observations which directly link hypoxia in obesity to the associated insulin resistance independently of adipokines. As such, factors that are widely implicated in the modulation of insulin sensitivity, for instance adiponectin and IL-6, may in practise exacerbate insulin resistance rather than being critical to its initiation.

\section{Interactions: hypoxia and fatty acids}

Studies to date have essentially considered the effects of hypoxia independent of other influences on adipocyte function. In recent experiments, we have begun to explore the potential interaction between low $\mathrm{O}_{2}$ tension and other factors which affect adipocytes, and in particular fatty acids. In these experiments, human adipocytes have been incubated with different fatty acids in both normoxia and hypoxia. Initial studies suggest that some long-chain fatty acids can modulate the effects of hypoxia on the expression of certain genes - responses that are both gene and fatty acid selective. For example, while neither hypoxia $\left(1 \% \mathrm{O}_{2}\right)$ nor palmitate $(250 \mu \mathrm{M})$ alone increase IL-1 $\beta$ mRNA level, together they have a stimulatory effect on the expression of this key inflammatory cytokine (de Oliveira et al., unpublished results). Similarly, palmitate and hypoxia have an additive effect on IL-6 and Angplt4 expression, but this does not occur with oleate (González-Muniesa et al., unpublished results).

Apart from demonstrating the principle of selective interactions between low $\mathrm{O}_{2}$ tension and other factors that can influence fat cell function, these exploratory studies suggest that the release of fatty acids from adipocytes following the activation of lipolysis could in some cases amplify the effects of hypoxia (and vice versa), particularly with respect to the production of inflammation-related factors. This could also be the case with fatty acids derived from the circulation.

\section{Hypoxia and preadipocytes}

Several studies have indicated that hypoxia inhibits the differentiation of preadipocytes into adipocytes (37-39). This appears to involve, at least in part, a hypoxia-induced suppression of the expression of the PPAR $\gamma$ nuclear transcription factor which plays a central role in adipocyte differentiation (37). Most studies have focused on murine adipocyte systems, but our own studies have indicated that the differentiation of human preadipocytes is also suppressed by hypoxia (Wang, unpublished results) and PPAR $\gamma$ 
gene expression is inhibited (40).

We have also examined the effects of hypoxia on the expression and release of several key adipokines by preadipocytes. The most dramatic observations related to leptin (40). This hormone is not normally synthesised by preadipocytes, its expression and secretion being differentiation-dependent, with leptin mRNA being essentially undetectable. However, incubation of human preadipocytes in hypoxia results in a substantial induction of leptin gene expression. Furthermore, immunoreactive leptin is readily detectable in the medium of the cells, demonstrating that preadipocytes synthesise and secrete the hormone in response to low $\mathrm{pO}_{2}$. Whether preadipocyte-derived leptin following hypoxia in adipose tissue would make a significant contribution to the circulating level of the hormone is highly problematic. It may, nonetheless, be of importance locally within the tissue through a paracrine role.

Other cells within adipose tissue may also be subject to hypoxia. The most obvious are the macrophages that are now recognised to be recruited into the tissue in obesity and which are considered to contribute to the development of inflammation $(41,42)$. Hypoxia stimulates gene expression in macrophages, leading to an augmentation of the inflammatory response in the cells (17). It is also likely that the endothelial cells within adipose tissue will be subject to hypoxia and the expression of key genes modulated.

\section{Coda}

It is evident that hypoxia can have a pervasive effect on adipocyte function (Fig. 2). This ranges from inducing a switch towards glycolytic metabolism for the generation of ATP with the consequent production of excess lactate, to increasing the synthesis of key adipokines such as leptin and VEGF. The induction of insulin resistance, which may occur at several levels, is an important example of how a low $\mathrm{O}_{2}$ tension can directly lead to cell dysfunction. Although HIF-1 $\alpha$ appears to be a key factor in the transmission of the cellular response to hypoxia in adipocytes, it is important to consider the possible role of the HIF- $2 \alpha$ and HIF- $3 \alpha$ subunits of HIF, as well as that of other transcription factors.

As noted particularly in the case of preadipocytes, hypoxia has the potential to influence the function of the other cell types within white adipose tissue and not just adipocytes. This may in turn lead to amplification, or modulation, of the cross-talk between the different cells in the face of $\mathrm{O}_{2}$-deprivation. An im-

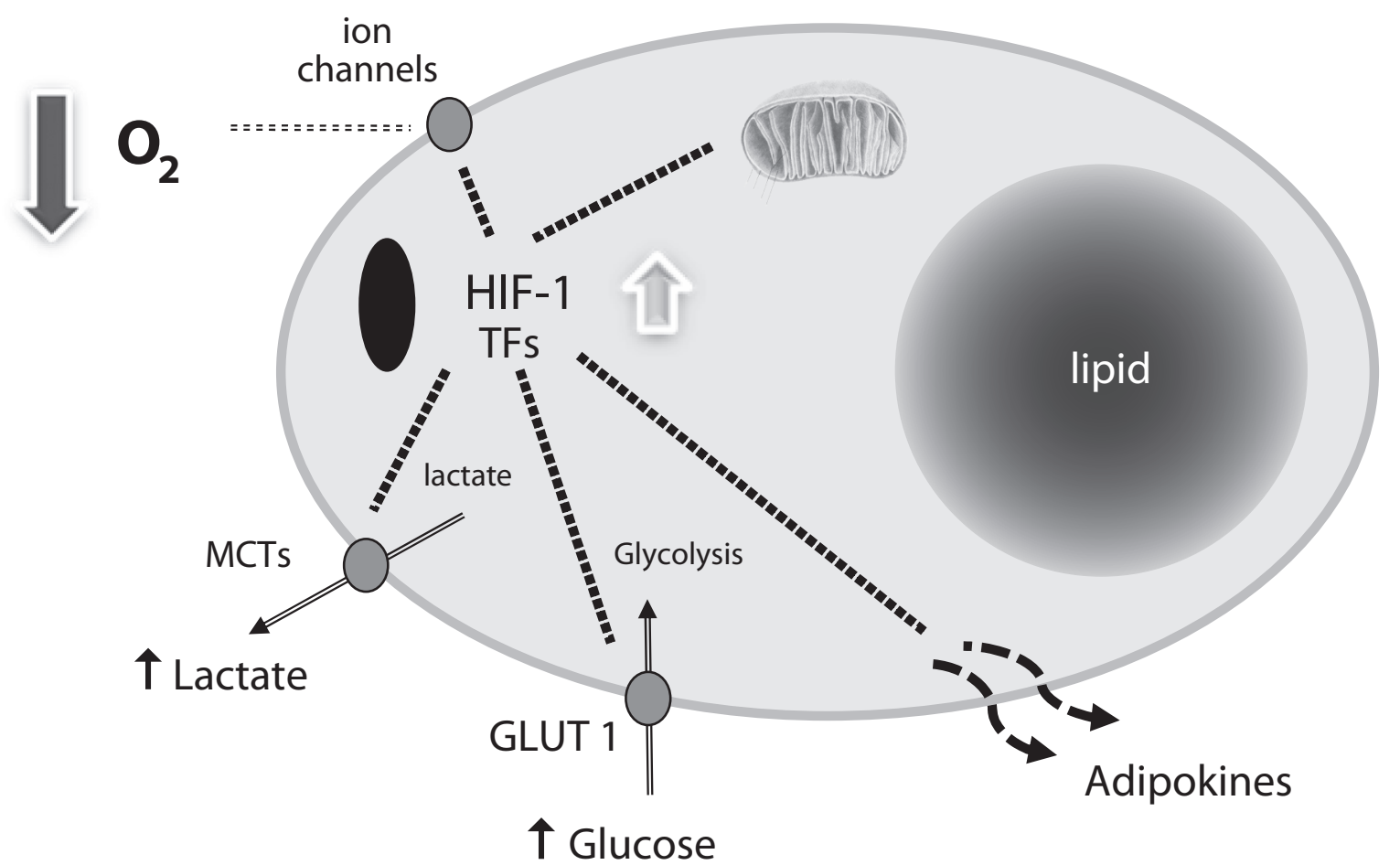

Figure 2. Summary of the effects of hypoxia on adipocyte metabolism. GLUT1, factilitative glucose transporter-1; HIF-1, hypoxia-inducible factor 1; MCTs, monocarboxylate transporters; TFs, transcription factors. 
portant issue is the mechanism by which low $\mathrm{pO}_{2}$ is sensed at the plasma membrane, and this is likely to involve specific hypoxiasensitive ion channels (43). Indeed, we have recently observed that expression of the KCNA1 (Kv1.1) ion channel is induced in human adipocytes by hypoxia (Wang et al, unpublished results); nevertheless, direct modulation of channel activity is of key importance to the acute signalling of low $\mathrm{O}_{2}$ tension.

\section{Acknowledgements}

We thank Drs Dawn Mazzatti and Fei-Ling Lim (Unilever plc), and Mr Adrian O'Hara (Obesity Biology Research Unit) for carrying out the microarrays of adipocytes exposed to hypoxia. We are grateful to the BBSRC (UK) for grant support for our work on hypoxia; FPdH gratefully acknowledges the receipt of a Fellowship from the Fundación Alfonso Martín Escudero (Spain). $\mathrm{PT}$ is a member of COST BM0602.

\section{References}

1. Semenza GL. Targeting HIF-1 for cancer therapy. Nat Rev Cancer 2003; 3: 721-732.

2. Brahimi-Horn MC, Pouysségur J. Oxygen, a source of life and stress. FEBS Lett 2007; 581: 3582-3591.

3. Trayhurn P, Wood IS. Adipokines: Inflammation and the pleiotropic role of white adipose tissue. Br J Nutr 2004; 92: 347-355.

4. Skurk T, Alberti-Huber C, Herder C, Hauner H. Relationship between adipocyte size and adipokine expression and secretion. J Clin Endocrinol Metab 2007; 92: 1023-1033.

5. Trayhurn P, Wang B, Wood IS. Hypoxia in adipose tissue: A basis for the dysregulation of tissue function in obesity? $\mathrm{Br} J$ Nutr 2008; 100: 227-235.

6. Trayhurn P, Beattie JH. Physiological role of adipose tissue: White adipose tissue as an endocrine and secretory organ. Proc Nutr Soc 2001; 60: 329-339.

7. Frühbeck G, Salvador J. Role of adipocytokines in metabolism and disease. Nutr Res 2004; 24: 803-826.

8. Rajala MW, Scherer PE. The adipocyte - at the crossroads of energy homeostasis, inflammation, and atherosclerosis. Endocrinology 2003; 144: 3765-3773.

9. Rosen ED, Spiegelman BM. Adipocytes as regulators of energy balance and glucose homeostasis. Nature 2006; 444: 847-853.

10. Wellen KE, Hotamisligil GS. Inflammation, stress, and diabetes. J Clin Invest 2005; 115: 1111-1119.

11. Hotamisligil GS. Inflammation and metabolic disorders. Nature 2006; 444: 860-867.

12. Arita $\mathrm{Y}$ et al. Paradoxical decrease of an adipose-specific protein, adiponectin, in obesity. Biochem Biophys Res Com- mun 1999; 257: 79-83.

13. Yudkin JS. Adipose tissue, insulin action and vascular disease: Inflammatory signals. Int J Obesity 2003; 27 (Suppl 3): S25-S28.

14. Cummins EP, Taylor CT. Hypoxia-responsive transcription factors. Pflügers Arch Eur J Physiol 2005; 450: 363-371.

15. Rocha S. Gene regulation under low oxygen: Holding your breath for transcription. Trends Biochem Sci 2007; 32: 389397.

16. Hosogai $\mathrm{N}$ et al. Adipose tissue hypoxia in obesity and its impact on adipocytokine dysregulation. Diabetes 2007; 56: 901-911.

17. Ye J, Gao Z, Yin J, He Q. Hypoxia is a potential risk factor for chronic inflammation and adiponectin reduction in adipose tissue of $o b / o b$ and dietary obese mice. Am J Physiol Endocrinol Metab 2007; 293: E1118-E1128.

18. Rausch ME, Weisberg SP, Vardhana P, Tortorielllo DV. Obesity in C57BL/6J mice is characterised by adipose tissue hypoxia and cytotoxic t-cell infiltration. Int J Obesity 2008; 32: 451-463.

19. Pasarica $\mathrm{M}$ et al. Reduced adipose tissue oxygenation in human obesity: Evidence for rarefaction, macrophage chemotaxis, and inflammation without an angiogenic response. Diabetes 2009; 58: 718-725.

20. Trayhurn P, Wang B, Wood IS. HIF-1a protein rather than mRNA as a marker of hypoxia in adipose tissue in obesity: Focus on "Inflammation is associated with a decrease of lipogenic factors in omental fat in women," By PoulainGodefroy et al. Am J Physiol Regul Integr Comp Physiol 2008; 295: R1097.

21. Lolmède K, Durand de Saint Front V, Galitzky J, Lafontan M, Bouloumié A. Effects of hypoxia on the expression of proangiogenic factors in differentiated 3T3-F442A adipocytes. Int J Obesity 2003; 27: 1187-1195.

22. Chen B et al. Hypoxia dysregulates the production of adiponectin and plasminogen activator inhibitor-1 independent of reactive oxygen species in adipocytes. Biochem Biophys Res Commun 2006; 341: 549-556.

23. Wang B, Wood IS, Trayhurn P. Dysregulation of the expression and secretion of inflammation-related adipokines by hypoxia in human adipocytes. Pflügers Archiv Eur J Physiol 2007; 455: 479-492.

24. Wood IS, Wang B, Lorente-Cebrián S, Trayhurn P. Hypoxia increases expression of selective facilitative glucose transporters (GLUT) and 2-deoxy-D-glucose uptake in human adipocytes. Biochem Biophys Res Commun 2007; 361: 468473.

25. Regazzetti C, Peraldi P, Grémeaux T, Najem-Lendom R, 
Ben-Sahra I, Cormont M, et al. Hypoxia decreases insulin signaling pathways in adipocytes. Diabetes 2009; 58: 95-103.

26. Wabitsch M, Brenner RE, Melzner I, Braun M, Möller P, Heinze E, et al. Characterization of a human preadipocyte cell strain with high capacity for adipose differentiation. Int J Obes Relat Metab Disord 2001; 25: 8-15.

27. Wood IS, Wang B, Trayhurn P. Il-33, a recently identified interleukin-1 gene family member, is expressed in human adipocytes. Biochem Biophys Res Commun 2009; 384: 105-109.

28. Wang B, Wood IS, Trayhurn P. PCR arrays identify metallothionein-3 as a highly hypoxia-inducible gene in human adipocytes. Biochem Biophys Res Commun 2008; 368: 88-93.

29. Tanji K, Irie Y, Uchida Y, Mori F, Satoh K, Mizushima Y, et al. Expression of metallothionein-III induced by hypoxia attenuates hypoxia-induced cell death in vitro. Brain Res 2003; 976: 125-129.

30. Pérez de Herédia F, Wood IS, Trayhurn P. Hypoxia modulates monocarboxylate transporter (MCT) expression in human adipocytes. Proc Nutr Soc 2009; 68: in print.

31. Halestrap A, Meredith D. The SLC16 gene family - from monocarboxylate transporters (MCTS) to aromatic amino acid transporters and beyond. Pflügers Archiv Eur J Physiol 2004; 447: 619-628.

32. Ullah MS, Davies AJ, Halestrap AP. The plasma membrane lactate transporter MCT4, but not MCT1, is up-regulated by hypoxia through a HIF-1 $\alpha$-dependent mechanism. J Biol Chem 2006; 281: 9030-9037.

33. Semenza GL. Oxygen-dependent regulation of mitochondrial respiration by hypoxia-inducible factor 1 . Biochem $J$ 2007; 405: 1-9.

34. Fukuda R, Zhang H, Kim JW, Shimoda L, Dang CV, Semenza GL. HIF-1 regulates cytochrome oxidase subunits to optimize efficiency of respiration in hypoxic cells. Cell 2007; 129: 111-122.
35. Pérez de Herédia F, Wood IS, Trayhurn P. Acute and chronic hypoxia selectively modulates the expression of glucose transporters (GLUTs) in human adipocytes. Obesity Facts 2009; 2 (Suppl 2): 39.

36. Yin J, Gao Z, He Q, Zhou D, Guo Z, Ye J. Role of hypoxia in obesity-induced disorders of glucose and lipid metabolism in adipose tissue. Am J Physiol Endocrinol Metab 2009; 296: E333-E342.

37. Yun Z, Maecker HL, Johnson RS, Giaccia AJ. Inhibition of PPAR gamma 2 gene expression by the HIF-1-regulated gene DEC1/stra13: A mechanism for regulation of adipogenesis by hypoxia. Dev Cell 2002; 2: 331-341.

38. Zhou S, Lechpammer S, Greenberger JS, Glowacki J. Hypoxia inhibition of adipocytogenesis in human bone marrow stromal cells requires transforming growth factor- $\beta$ / Smad3 signaling. J Biol Chem 2005; 280: 22688-22696.

39. Kim KH, Song MJ, Chung J, Park H, Kim JB. Hypoxia inhibits adipocyte differentiation in a HDAC-independent manner. Biochem Biophys Res Commun 2005; 333: 11781184.

40. Wang B, Wood IS, Trayhurn P. Hypoxia induces leptin gene expression and secretion in human preadipocytes: Differential effects of hypoxia on adipokine expression by preadipocytes. J Endocrinol 2008; 198: 127-134.

41. Weisberg SP, McCann D, Desai M, Rosenbaum M, Leibel RL, Ferrante AW Jr. Obesity is associated with macrophage accumulation in adipose tissue. J Clin Invest 2003; 112: 1796-1808.

42. Xu H, Barnes GT, Yang Q, Tan G, Yang D, Chou CJ, et al. Chronic inflammation in fat plays a crucial role in the development of obesity-related insulin resistance. J Clin Invest 2003; 112: 1821-1830.

43. Lopéz-Barneo J, Pardal R, Ortéga-Saenz P. Cellular mechanism of oxygen sensing. Annu Rev Physiol 2001; 63: 259-287. 